Rectangular-Polar Conversion Tables

Designed and compiled by E. H. Neville. (Royal Society Mathematical Tables, Vol. 2.) Pp. xxxii + 109. (Cambridge: At the University Press, 1956. Published for the Royal Society.) 30s. net.

$\mathrm{T}$ HE problem of determining the polar coordinates $(r, \theta)$ of a point with Cartesian coordinates $(x, y)$, according to the equations $x=$ $r \cos \theta, y=r \sin \theta$, is a common one presenting no theoretical difficulty. In particular, the solution of algebraic equations by root-squaring necessitates the conversion in complex form (that is, $z=x+i y=$ $r e^{i \theta}$ ), and (to quote the author's words) without a quick passage between corresponding pairs of values, the process is a flight of fancy rather than a technical revolution.

Almost all the tables hitherto available for the above conversion have been single-entry in character, employing the argument $t=y / x$ and then working in terms of arc tan $t$ and $\sqrt{ }\left(1+t^{2}\right)$. The use of two independent variables, for which purpose this volume is primarily designed, clearly facilitates the calculations and obviates the danger of serious numerical errors.

The table covers the triangular range $1 \leqslant y \leqslant x \leqslant 105$, the upper limit 105 being chosen as convenient for typographical purposes. The arrangement of the entries is extremely ingenious, each page containing exactly 106 pairs of entries to 15 decimal places. To explain the detail of the arrangement, it is sufficient to take a page at random, say p. 35 , and to describe its contents. These are $x=35, y=1(1) 35$, with values of $r$ and $\theta$ in degrees, followed by $y=35$, $x=35(1) 105$, with values of $\log _{e} r$ and $\theta$ in radians. As will thus be seen, the logarithm table not only provides symmetry but also avoids repetition.

A substantial introduction precedes the main table just described and is mainly concerned with methods of interpolation required in using the table. Many illustrative examples are provided, and no effort has been spared to clarify the details of the numerical computation involved.

A bibliography of relevant and collateral tables is also provided, and the volume concludes with six supplementary tables, which include page-indexes for $r$ and $\log _{e} r$ and the first 1,688 integer-denominators of the Farey series of order 105, the use of which is required in the interpolation methods.

J. H. Pearce

Second Thoughts on Radio Theory

By "Cathode Ray" of Wireless World. Pp. 409. (London: Iliffe and Sons, Ltd., 1955. Published for Wireless World.) 25s. net.

THIS collation of articles contributed by "Cathode Ray" to the Wireless World during the past twenty-five years forms a kind of running commentary on the development of radio theory during the period. The impenetrable pseudonym might stand for a synthetic figure, made up of experts of the panel ; but the characteristic manner of writing suggests that one person, and a very forceful person, too, is the author of them all. In any event, one feels that during this period few individuals can have done more to encourage and browbeat radio engineers to face fundamental difficulties and think out the solutions for themselves.

The book contains some forty articles on basic ideas, circuit elements and techniques, and cal. culations. Each article starts in a simple fashion; but the topic is dissected and discussed so thoroughly in detail that towards the end the reader is being piloted skilfully through the deeps. The light conversational style which is "Cathode Ray's" own way of driving his points home may not appeal to everybody; but there is wisdom and sound judgment behind it. Intolerance of jargon and slipshod thinking, and an irreverence towards the pundits who frame definitions in a spirit of confusion, flash out fiercely from time to time. It is good to see so many of these articles together in permanent form, and the publishers are to be congratulated on an excellent volume.

G. R. Noakes

The Biology of a Marine Copepod

Calanus finmarchicus (Gunnerus). By Dr. S. M. Marshall and Dr. A. P. Orr. Pp. vii $+188+18$ plates. (Edinburgh and London: Oliver and Boyd, Ltd., 1955.) 21s. net.

TEARLY two hundred years ago Calanus was discovered in northern Norwegian waters and classified by its discoverer, Bishop Gunnerus of Trondheim, as Monoculus finmarchicus among the "Insecta Aptera". As an important link in the marine food chain, especially as a staple food of the herring, this copepod has become the object of study of workers in a great variety of branches of biology.

'The authors, having themselves worked on Calanus for many years, have written a well-produced and eminently readable survey of knowledge concerning the systematics and distribution, the anatomy, reproduction, development and life-cycle of the animal. Chapters dealing with biometrical data, the animal's chemical composition, its food and feeding mechanism, lead to a summary of work on its respiration, vertical migration, and its relation to inorganic and organic environment.

An extensive list of references and a most carefully prepared index add to the value of a book which should prove to be an asset to zoologists, marine biologists and naturalists alike.

\section{Clays and Clay Minerals}

Proceedings of the Second National Conference on Clays and Clay Minerals, University of Missouri, October 15-17, 1953. Edited by Ada Swineford and Norman Plummer. (Sponsored by the Committee on Clay Minerals of the National Academy of SciencesNaúional Research Council ; University of Missouri ; State Geological Survey of Kansas.) Pp. viii +504 . (Washington, D.C. : Publication 327, National Academy of Sciences-National Research Council, 1954.) 4 dollars.

DRING recent years the study of clays and clay Dinerals has received much attention, and the widespread interest in the subject has been fostered by the establishment of national and international groups and committees. In the United States, a National Conference on Clays and Clay Minerals, the second of its kind, was held at the University of Missouri in the autumn of 1953, and this volume is a record of the proceedings. It contains thirty-seven separate contributions from authors with a wide variety of experience, dealing with the geology, genesis, chemistry, mineralogy, crystal structure and physical and mechanical properties of clay deposits and clay minerals, and includes a number of X-ray studies. The volume is well printed and illustrated, and adequately indexed, and forms a valuable contribution to the literature of clays. 